\title{
Reducing uncertainty in managing respiratory tract infections in primary care
}

\author{
Naomi Stanton, Nick A Francis and Chris C Butler
}

\begin{abstract}
Respiratory tract infections (RTIs) remain the commonest reason for acute consultations in primary care in resource-rich countries. Their spectrum and severity has changed from the time that antibiotics were discovered, largely from improvements in the socioeconomic determinants of health as well as vaccination. The benefits from antibiotic treatment for common RTIs have been shown to be largely overstated. Nevertheless, serious infections do occur. Currently, no clinical features or diagnostic test, alone or in combination, adequately determine diagnosis, aetiology, prognosis, or response to treatment. This narrative review focuses on emerging evidence aimed at helping clinicians reduce and manage uncertainty in treating RTIs. Consultation rate and prescribing rate trends are described, evidence of increasing rates of complications are discussed, and studies and the association with antibiotic prescribing are examined. Methods of improving diagnosis and identifying those patients who are at increased risk of complications from RTIs, using clinical scoring systems, biomarkers, and point of care tests are also discussed. The evidence for alternative management options for RTIs are summarised and the methods for changing public and clinicians' beliefs about antibiotics, including ways in which we can improve clinician-patient communication skills for management of RTls, are described.

Keywords

anti-bacterial agents; cough; primary health care; respiratory tract infections.
\end{abstract}

N Stanton, MRCGP, DCH, clinical research fellow; NA Francis, $B A, P h D, M D, M R C G P$, senior clinical research fellow; CC Butler, BA, MD, DCH, FRCGP, CCH, HonFFPH, , professor of primary care medicine, Department of Primary Care and Public Health, Cardiff University, Cardiff.

Address for correspondence

Professor Chris C Butler, Cardiff University, Department of Primary Care and Public Health, Neuadd Meirionnydd, Heath Park, Cardiff CF14 4YS. E-mail: butlercc@cardiff.ac.uk

Submitted: 23 June 2009; Editor's response: 19 April 2010; final acceptance: 15 June 2010.

(O)British Journal of General Practice.

This is the full-length article (published online 29 November 2010) of an abridged version published in print. Cite this article as: Br J Gen Pract 2010; DOI: 10.3399/bjgp10X544104

\section{BACKGROUND}

Respiratory tract infections (RTIs) remain the commonest reason for acute consultations in primary care in resource-rich countries. Their spectrum and severity have changed from the time that antibiotics were discovered, when the mortality rate from pneumococcal pneumonia was over $20 \%$ (rising to $60 \%$ with associated bacteraemia). ${ }^{1}$ Penicillin was considered a 'wonder drug' at that time, and antibiotic treatment gradually became the norm even for mild respiratory infections. However, the decline in morbidity and mortality from infectious diseases in the 20th century flowed largely from improvements in the socioeconomic determinants of health (such as, basic hygiene and sanitation), as well as vaccination, and the benefits from antibiotic treatment for common RTIs has been shown to have been largely overstated. ${ }^{2}$ Nevertheless, serious infections that might be prevented by early antibiotic treatment still occur. Therefore, while these consultations are often considered the 'bread and butter' of general practice, they are made challenging by the need to manage diagnostic and prognostic uncertainty. No clinical features or current diagnostic test, alone or in combination, adequately determine diagnosis, aetiology, prognosis, or response to treatment. This narrative review focuses on emerging evidence aimed at helping clinicians reduce and manage uncertainty in treating RTIs. Medline was searched using the following terms: respiratory tract infections, diagnosis, prognosis, and management for relevant references, and The Cochrane Database Acute Respiratory Infections Group was searched for relevant systematic reviews.

\section{Antibiotic prescribing}

Antibiotic prescribing in primary care steadily increased in developed countries up until the 1990s when it levelled off and then declined by about a third. ${ }^{3,4}$ However, despite robust evidence from observational studies and randomised controlled trials highlighting little or no benefit from antibiotic treatment for most people presenting with RTI symptoms, these illnesses are still the commonest reason for antibiotic prescribing in primary care, ${ }^{5}$ and prescribing rates have now stopped declining and may be increasing again. ${ }^{4}$ 
Antibiotic prescribing puts individuals at risk from side effects, encourages help-seeking behaviour for (mainly) self-limiting illnesses, and puts both individuals and society at risk from increasing antibiotic resistance. ${ }^{6}$ Many GPs do not link their own prescribing practices with increasing antibiotic resistance and regard resistance as essentially a hospital-based problem. ${ }^{7}$ There is wide variation in antibiotic prescribing across Europe, ${ }^{8-10}$ and within the UK, ${ }^{11}$ with no evidence that this is associated with differing disease spectrum or complication rates. ${ }^{8}$

The 2008 National Institute for Clinical Excellence (NICE) guidelines recommend no antibiotics or delayed antibiotics for most patients with RTI (Box 1). ${ }^{12}$

\section{Consultation rates}

One reason antibiotic prescribing declined in the 1990 s in the UK was a reduction in primary care consultations for RTIs. In adults, consultations declined from 74.5 visits per 1000 person-years in 1990 to 50.2 visits per 1000-person years in 2004, and consultations declined in children from 247.9 per 1000 person-years in 1990 to 154.5 per 1000 person-years in $2004 .{ }^{4}$ However, since 2000 , as with antibiotic prescribing, consultation rates have started to increase again. ${ }^{4}$ The reasons are unclear.

\section{Re-consultations for the same illness episode}

Between $15 \%$ and $20 \%$ of children with RTls reconsult during the same illness episode, ${ }^{13,14}$ and between $20 \%$ and $30 \%$ of adults with lower RTls (LRTIs) will reconsult. ${ }^{15-17}$ Reconsultations provide an opportunity for patients (and parents) with new concerns to have these addressed. However, they can be a marker that patient (parent) concerns were not adequately addressed during the first consultation. ${ }^{16}$ Reconsulting can increase the pressure to prescribe (unnecessary) antibiotics. Between a half ${ }^{16}$ and twothirds $^{15}$ of adults with LRTI who reconsult are prescribed antibiotics, despite little evidence of an infection requiring antibiotics. ${ }^{15}$ Strategies to address patient concerns during the initial consultation may therefore reduce unnecessary re-consultations.

\section{Complications}

Quinsy. The evidence for antibiotics for sore throat preventing quinsy comes largely from a single study in the 1950s of intramuscular penicillin. ${ }^{18}$ More recent studies have included only nine cases of quinsy between them, ${ }^{6,19-21}$ so robust conclusions are inappropriate.

A UK case-control study using General Practice Research Database (GPRD) data found that only onethird of people presenting with quinsy had been seen in primary care with a sore throat during that illness episode. Antibiotic treatment did not protect against

\section{How this fits in}

Respiratory tract infections are common and most benefit very little if at all from antibiotic treatment. Differentiating the few patients at higher risk from a

complicated course from the majority who will recover uneventfully remains a challenge, and antibiotics continue to be widely overused. Clinical prediction rules, identification of 'at risk' groups, near-patient tests, and better

communication regarding uncertainty (such as use of shared decision making, interactive booklets, and delayed prescribing) can all help target antibiotics to those most likely to benefit. Public health campaigns, reinforcing basic hygiene messages, and vaccination for at-risk groups also improve outcomes and reduce inappropriate antibiotics.

quinsy in those that did consult with sore throat before developing quinsy, although there was a nonsignificant trend towards antibiotics being beneficial in those who presented initially with tonsillitis. ${ }^{22}$

A study of over a million cases of sore throat in the GPRD found antibiotic treatment was associated with a reduction in quinsy within the following month. However, the incidence of quinsy was low and 4300

\section{Box 1. Summary of NICE guidance on antibiotic prescribing for} self-limiting respiratory tract infections in primary care. ${ }^{12}$

Prescribe antibiotics for immediate use and/or arrange further appropriate investigation and management for the following patients:

- Those who are systemically very unwell

- Those with symptoms and signs suggesting serious illness and/or complications (particularly pneumonia, mastoiditis, peritonsillar abscess, peritonsillar cellulitis, intraorbital and intracranial complications)

- Those at high risk of serious complications because of pre-existing comorbidity (including patients with heart, lung, renal, liver, or neuromuscular disease, immunosuppression, or cystic fibrosis, and young children who were born prematurely)

- Those who are $>65$ years with acute cough and two or more of the following criteria, or $>80$ years with one or more of the following criteria:
Admission to hospital in previous year
Diabetes (type 1 or type 2)
- History of congestive heart failure
Current use of glucocorticoids

Consider prescribing antibiotics for immediate use in the following situations:

- Bilateral acute otitis media in children under 2 years

- Acute otitis media in children with otorrhoea

- Acute sore throat or acute tonsillitis when $\geq 3$ Centor criteria are present

For all others adults and children (over 3 months) with acute otitis media, acute sore throat (or tonsillitis), common cold, acute rhinosinusitis, acute cough, or acute bronchitis, a non-prescribing or delayed-prescribing approach should be adopted.

Explore the patient's concerns and expectations, and consider these when discussing management options.

Advise on the usual course of the illness and the average total illness duration. Advise patients how to manage symptoms, including fever.

Provide advice and when to re-consult and /or use a delayed prescription. 
patients with sore throat would need to be treated to prevent one case of quinsy. ${ }^{23}$ Furthermore, within the 1065088 cases of sore throat, there were 'virtually no cases' of acute rheumatic fever or acute glomerulonephritis after sore throat. ${ }^{23}$

Mastoiditis following acute otitis media. Two large retrospective GPRD studies found that treating acute otitis media with antibiotics may prevent mastoiditis, but the number needed to treat (NNT) was over $4000 .{ }^{23,24}$ Most (two-thirds) had not seen their GP prior to developing mastoiditis, and therefore did not have the opportunity to benefit from antibiotic treatment.

These conclusions are broadly supported by a timetrend analysis of UK hospital admission data. A 34\% reduction in GP prescribing to children (the group in which these complications predominantly occur) between 1993 and 2002 was not associated with an increase in admission rates of quinsy or rheumatic fever. Data on the incidence of mastoiditis was conflicting, with an increase in hospital episodes of mastioditis and simple mastoidectomy, but a reduction in these events during the same time period in data from a general practice database. ${ }^{25}$

Pneumonia following LRTI. The age-standardised incidence of hospital admissions for pneumonia increased by 34\% between 1997-1998 and 2004-2005. ${ }^{26}$ Pneumonia and empyema in children are also becoming more common. ${ }^{27}$

Three retrospective studies of GPRD data explored the role of antibiotic prescribing in primary care in preventing subsequent pneumonia. The first analysed pneumonia mortality, influenza incidence, and antibiotic prescribing for LRTI in England and Wales during 12-week winter periods between 1993/1994 and 1999/2000. There was a decline in winter antibiotic prescribing for LRTI of $30.0 \%$ since 1995/1996 and a $50.6 \%$ increase in winter excess pneumonia mortality, adjusted for influenza incidence, over the same time frame. ${ }^{28}$ The reduction in antibiotic prescribing was significantly associated with pneumonia-related mortality $(P<0.001)$, after controlling for influenza incidence.

The second study found antibiotic prescribing for 'chest infection' was associated with a reduction in pneumonia in the month after a LRTI diagnosis. This was most marked for those aged $>65$ years, with a NNT to prevent one case of pneumonia of $39 . .^{23}$ However, neither 'chest infection' nor 'pneumonia' are clearly defined diagnoses in primary care. It is possible that clinicians are more likely to make a diagnosis of pneumonia in patients with a cough and some features suggesting a LRTI when they have already decided to treat the patient with antibiotics, and are more likely to diagnose a 'chest infection' when a decision not to prescribe antibiotics has been made (confounding by indication). ${ }^{29}$ Therefore, patients who have been diagnosed with a 'chest infection' and who subsequently re-consult (possibly because of unrealistic expectations about natural illness course) may be more likely to then be diagnosed with pneumonia.

The third study found that patients with LRTI who were not treated with antibiotics were at greater risk of respiratory infection-related hospital admissions and death. ${ }^{30}$ However, the NNT to prevent one hospital admission and one death respectively, were 1002 and 7247.30

Retrospective studies like these based on routinely collected data have inherent weaknesses (including problems with diagnosis coding, and illness definition), and the assumed NNT are generally very large. These NNTs are in a sense spurious: retrospective observational data cannot reassure practitioners that, had these people received antibiotics in primary care, they would not have developed the complication. Only large prospective studies can confidently attribute causality.

Nevertheless, these studies suggest an association between recent reductions in antibiotic prescribing for LRTI in general practice and an increase in pneumonia mortality in England and Wales. ${ }^{28}$ Therefore, the question remains not whether all patients with LRTI should be treated with antibiotics, but how to identify the minority who will benefit.

\section{Improving diagnostic accuracy}

Clinical judgement alone lacks specificity in differentiating serious from mild infection. An Australian study of acutely unwell children presenting in the emergency department (ED) found that although the incidence of serious infection was low $(3.4 \%$ for pneumonia, $3.4 \%$ for UTI, and $0.7 \%$ for bacteraemia), between $20-30 \%$ of these children were not identified as having serious infections on clinical presentation, and did not receive immediate antibiotics. In addition, $20 \%$ of children without identifiable bacterial infection received antibiotics. ${ }^{31}$

\section{Clinical prediction rules}

Sore throat. Group A Streptococcus (GAS) is the most common and important cause of sore throat that may benefit from antibiotic treatment. ${ }^{32}$ The probability of detecting GAS in patients presenting with an acute sore throat is $5-40 \%,{ }^{33-41}$ depending on clinical setting (higher in EDs and lower in primary care), season (higher in autumn and winter), age (higher in children, lower in adults), and clinical symptoms and signs. Diagnostic error is associated with unnecessary antibiotic prescribing. ${ }^{42}$

The Centor ${ }^{35}$ and modified Centor ${ }^{43}$ scores (Box 2) 
have been validated in clinical trials. The prevalence of GAS increases with Centor score from $<5 \%$ for those with scores of 0 or 1 to $60.3 \%$ for those with a score of $4 .{ }^{39}$

Similar clinical findings to those used in the Centor score (pharyngeal exudates and tender anterior cervical nodes) were identified as being most predictive of GAS in a review of the precision and accuracy of clinical examination in nine prospective sore throat studies. ${ }^{44}$

\section{LRTI}

Individual clinical symptoms and signs have poor predictive value to differentiate pneumonia from bronchitis. ${ }^{45-48}$ Emphasis has shifted from differentiating viral from bacterial infections to differentiating those patients who are more likely to benefit from antibiotics from those who are unlikely to benefit. ${ }^{49}$

Biomarkers and point-of-care tests. Two biomarkers potentially useful in differentiating self-limiting from more serious infections are C-reactive protein (CRP) and procalcitonin. A systematic review of the diagnostic value of CRP testing in LRTIs, ${ }^{50}$ and a more recent comparison of $\mathrm{CRP}$ and procalcitonin testing for LRTI, ${ }^{51}$ found neither test sufficiently sensitive or specific to differentiate bacterial pneumonia from bronchitis. However, biomarker testing may be helpful in safely reducing antibiotic prescribing for LRTI, mainly through ruling out the need for antibiotic treatment.

Procalcitonin testing has been evaluated in an open randomised controlled trial of 1359 patients with LRTI symptoms (68\% diagnosed with community-acquired pneumonia [CAP]) presenting to six EDs in Switzerland where $97.5 \%$ were treated as inpatients. Patients randomised to treatment based on procalcitonin monitoring received significantly fewer antibiotics without resulting in differences in clinical outcomes or adverse events. ${ }^{52}$

Biomarkers need to be available as a point-of-care tests (POCT) to be useful for guiding empirical antibiotic treatment in primary care. CRP is currently available as a POCT that can be done in the surgery in about 4 minutes, and CRP POCTs are widely used in some parts of Europe (but not the UK) to guide antibiotic prescribing decisions. Procalcitonin POCT tests are being developed.

A community-based trial of CRP POCT and communication skills training found that both interventions resulted in independent statistically significant reductions in antibiotic prescribing for LRTI, without adversely affecting recovery or patient satisfaction. ${ }^{53}$ However, this efficacy study required all patients to be CRP tested and the outcome was antibiotic prescribing in a limited number of consultations.

\section{Box 2. Centor Score (and Modified Centor Score ${ }^{\mathrm{b}}$ ).}

Add up points:

- History of fever or measured temperature $>38^{\circ} \mathrm{C}$

- Absence of cough ${ }^{\mathrm{a}, \mathrm{b}}$

- Tender anterior cervical adenopathy $y^{\mathrm{a}, \mathrm{b}}$

- Tonsillar swelling or exudates ${ }^{\mathrm{a}, \mathrm{b}}$

- Age $\leq 15$ years $^{\mathrm{b}}$

- Age $\geq 45$ years $^{b}$

LR of streptococcal throat infection:

Scores

LR

$-1^{\mathrm{b}}$ or $0^{\mathrm{a}, \mathrm{b}}$

$0.05^{\mathrm{b}}-0.16^{\mathrm{a}}$

$1^{\mathrm{a}, \mathrm{b}}$

$0.3^{\mathrm{a}}-0.52^{\mathrm{b}}$

$2^{\mathrm{a}, \mathrm{b}}$

$3^{\mathrm{a}, \mathrm{b}}$

$0.75^{\mathrm{a}}-0.95^{\mathrm{b}}$

$4^{\mathrm{a}, \mathrm{b}}$ or $5^{\mathrm{b}}$

$2.1^{\mathrm{a}}-2.5^{\mathrm{b}}$

$4.9^{\mathrm{b}}-6.3^{\mathrm{a}}$

${ }^{a}$ Centor. ${ }^{b}$ Mclsaac (modified Centor). $L R=$ likelihood ratio

In everyday practice, GPs will not test all patients, and further studies are needed to determine the effect of providing testing facilities to practices: how often would they use it? Would it have the same impact on antibiotic prescribing?

Qualitative research exploring GPs attitudes to POCTs found enthusiasm for a hypothetical POCT finger-prick blood test that could distinguish viral from bacterial infection. ${ }^{54}$ GPs emphasised that such a test would be most valuable in 'selling' decisions not to prescribe antibiotics to patients. Clinicians were concerned about the limited additional useful information from further tests compared to clinical diagnosis alone, that patients might deteriorate even if the tests correctly identified a viral aetiology, lack of pragmatic research evidence supporting uptake, and felt that the tests would be only ever be useful for a limited number of patients. Additional concerns included time pressures, apparatus maintenance and quality control, cost, and possible objections from patients, especially children. ${ }^{54}$

In UK primary care, antibiotics are prescribed for over $60 \%$ of patients presenting with sore throat. ${ }^{5}$ Empirical therapy based only on clinical score use results in inappropriate antibiotic prescribing. ${ }^{39,55}$ Rapid Streptococcal A throat (RSAT) swab POCTs are commonly used in parts of Europe and the US in an attempt to better target antibiotics. The best performing RSAT tests have a sensitivity of over $90 \%$ and a specificity of over $95 \%$ compared to throat swab cultures. $^{39,56,57}$ However, the interpretation of a positive GAS result is complicated by asymptomatic carriage. Between $8-52 \%$ of children and adolescents are healthy carriers of GAS. ${ }^{58}$ Carriage is higher in younger children.

A Swiss study of 372 consecutive adults presenting to an ED with a Centor score of 2-4 found that RSAT testing had high sensitivity (91\%) and specificity (95\%) 


\section{Box 3. Identifying patients at risk of poor prognosis for} developing pneumonia. ${ }^{63}$

- Chronic respiratory disease

- Chronic renal disease

- Chronic liver disease

- Diabetes

- Serious central nervous system diseases (cerebral vascular accident, transient ischaemic attack, Parkinson's disease, dementia, and multiple sclerosis)

- Rheumatoid arthritis

- Cancer

- Osteoporosis

- Increased age (>60 years), especially in the presence of: ${ }^{64}$ use of benzodiazepines or antidepressants

heart failure

$\rightarrow$ male sex

\section{Box 4. Risk factors for poor prognosis/hospitalisation from} lower respiratory tract infection.

Diabetes, especially in the presence of:

- Exacerbation of COPD

- Antibiotics within the previous month

- Pneumonia

- Heart failure

- Hospitalisation

- Current use of glucocorticoids or diabetic medication

Age $>80$ years, and:

- Diabetes (especially insulin dependent diabetes) ${ }^{65}$

- Exacerbation of COPD 65,66

- $\geq 2$ courses oral steroids in previous year ${ }^{65}$

- Recent antibiotic use ${ }^{65}$

- Housebound ${ }^{66}$

(Socioeconomic factors had little additive influence on outcomes) ${ }^{66}$

$C O P D=$ chronic obstructive pulmonary disease.

\section{Box 5. Risk factors for developing} quinsy. ${ }^{22}$

- Smoking

- Male sex

- Aged 21-40 years

for detecting GAS compared to culture, and that systematic RSAT testing in this group was more costeffective than empirical treatment, selective RSAT testing based on symptoms, or systematic culture. ${ }^{39}$

POCTs can rapidly detect certain viruses. A systematic review of four studies based in EDs concluded that use of rapid viral diagnostic tests for children presenting with acute febrile respiratory illness resulted in a significant reduction in chest X-rays, and a non-statistically significant trend towards reduced use of antibiotics and blood tests..$^{59}$ Larger trials are required.

Rapid POCTs for influenza $A$ and/or $\mathrm{B}^{60}$ along with tests for respiratory syncitial virus (RSV) ${ }^{61}$ are widely used in the US. The World Health Organization (WHO) advises rapid influenza POCT use at the beginning of the influenza season or an influenza outbreak to influence clinical decisions and contribute to clinical awareness. The $\mathrm{WHO}$, however, recognises that testing most people during high influenza activity is impractical. ${ }^{62}$

POCTs for Bordetella pertussis and mycoplasma are in development, but none of these are in routine use in the UK.

\section{Identifying patients at risk of a poor prognosis}

The NICE guidelines identify those at increased risk of complications from RTIs (Box 1). Risk factors for pneumonia and poor prognosis of LRTI are shown in Box 3 and 4, and risk factors for developing quinsy are in Box 5.

Most $(80 \%)$ of patients with CAP would prefer outpatient treatment, ${ }^{67,68}$ and a randomised controlled trial has demonstrated that patients at low risk of death who are treated as outpatients resume normal activity sooner than those who are hospitalised. ${ }^{69}$ Clinical scoring systems can add further prognostic information for patients with pneumonia and can therefore be helpful in determining the most appropriate treatment setting. Scoring systems for pneumonia severity include: the CURB (Confusion, Urea, Respiratory rate and Blood pressure), the CRB65 (as CURB, but with additional score for age $>65$ years and omission of Urea) and the PSI (the Pneumonia Severity Index). The PSI is less suitable for use in primary care because of its complexity; there are seven laboratory-based investigations required. The CURB and CRB-65 are both useful for assessing pneumonia severity and predicting risk of death in hospital and out-patient settings. ${ }^{68,70} \mathrm{~A}$ simplification of the CRB-65 score, which uses a cut-off point for only systolic blood pressure of $<90 \mathrm{mmHg}$ (that is, diastolic BP not included) performed equally well when compared to the standard CRB-65 score for the prediction of 30-day mortality (Box 6). ${ }^{71}$ Although no primary care study has validated these scoring systems or determined their impact on clinically relevant outcomes, the CRB-65 score is probably the most suitable tool for primary care, since it is quick and straightforward to use..$^{72}$ These scoring systems may perform less well in older people: a case-control study found that the CURB and CURB-65 scores performed poorly in those $\geq 75$ years old because respiratory rate, urea, and confusion were not independently associated with mortality in this age group. ${ }^{73}$

\section{Effectiveness of non-antibiotic treatments}

Non-antibiotic treatments for RTIs are summarised in Box 7 . 


\section{Modifying antibiotic prescribing}

Enhanced consultation skills. Antibiotics are more likely to be prescribed when patients expect them. ${ }^{91-93}$ However, patients frequently consult when antibiotics are not their main expectation, ${ }^{94,95}$ and clinicians are not able to discriminate well between those patients who expect and those who do not expect antibiotics. ${ }^{96}$ Perception of patient pressure is a strong independent predictor of antibiotic prescribing. ${ }^{93,97-99}$ It is a major driver in prescribing antibiotics when faced with normal chest auscultation. ${ }^{99}$

Consultations about RTIs are sometimes seen as an opportunity 'catch-up' and information-sharing can be inadequate. ${ }^{100}$ Sharing information about the likely natural history of RTIs helps set realistic expectations

\section{Box 6. Modified CRB-65 score. ${ }^{71}$}

1 point for each of the following:

- Age $>65$ years

- Presence of new onset pneumonia-associated mental confusion

- Hypotension with systolic blood pressure $<90 \mathrm{mmHg}$

- Respiratory rate $>30 /$ minute

Patients scoring no points are categorised as class 1, those with 1-2 points are categorised risk class 2, and those with 3-4 points are categorised as risk class 3. Patients meeting risk class 1 scores are candidates for ambulatory care provided there are no co-existent, decompensated comorbidities, pneumonia-related complications, or social factors requiring hospital care. ${ }^{69}$

about illness duration, which may reduce expectations (or perceived expectations) for antibiotics and reduce future consulting..$^{14}$

\section{Box 7. Summary of evidence for non-antibiotic management of RTls Cochrane Reviews.}

- Beta-2 agonists for acute bronchitis (mainly oral agents): little evidence for routine use in acute bronchitis in primary care, but if there is evidence of airflow obstruction with the symptoms, some adults may derive some symptomatic benefit. Only two included studies were in children, and there was no evidence of benefit. ${ }^{74}$

- Over-the-counter (OTC) medications for acute cough: review of antitussives, expectorants, mucloytics, antihistamine/decongestant combinations, other drug combinations and antihistamines concluded there was no good evidence for or against the effectiveness of OTC medications in children or adults, but that the few studies were mostly of poor design, with small sample sizes and that interventions and outcomes were so diverse that is was difficult to generalise the findings. ${ }^{75}$ In 2008 , the Commission on Human Medicines (CHM) advised about the unfavourable risk/benefit ratio of these medicines in children. The Medicines and Healthcare Regulatory Authority (MHRA) subsequently amended the product licence for cough medications for children due to safety concerns. ${ }^{76}$ They should not be used by children under 6 years of age, and can only be purchased for children aged 6-12 years in a pharmacy. The MHRA have also recommended that certain combinations should be phased out (the combination of cough suppressant and expectorant)

- Corticosteroids for sore throats: a systematic review and meta-analysis of eight trials involving 369 children and 374 adults found that despite heterogeneity, corticosteroids significantly reduced sore throat pain in addition to antibiotic therapy mainly in patients with severe or exudative sore throat. ${ }^{77}$

- Vitamin C for preventing and treating pneumonia: review of five trials carried out in extraordinary conditions suggested there may be a benefit at both preventing and treating pneumonia, but possibly only in those with low plasma vitamin $\mathrm{C}$ levels. ${ }^{78}$

- Vitamin C for preventing and treating the common cold: no benefit in the general population, but six trials which showed some evidence may reduce the risk of catching the common cold by half in individuals undergoing short periods of acute physical or cold stress or both (for example, marathon runners and soldiers training at sub-arctic conditions); poor study designs showed inconsistent results on effect of duration or severity of a cold. ${ }^{79}$

- Vitamin A for preventing acute LRTIs in children up to 7 years of age: some evidence for benefit if poor nutritional status, but some studies actually found increased chances of infection or worsened symptoms. ${ }^{80}$

- Echinacea for preventing and treating the common cold: some preparations based on Echinacea purpura might be effective, but no clear evidence of other preparation effectiveness or effectiveness in children. ${ }^{81}$

- Garlic for the common cold: only one study was eligible for inclusion and showed that people taking garlic every day for 3 months had fewer colds than those taking placebo, but the duration of a cold was similar in both groups; there have been no trials examining whether taking garlic at the time of a cold reduces severity or duration. ${ }^{82}$

- Chinese medicines for bronchitis, influenza, sore throats, and the common cold: no conclusion due to study design limitations and concerns over lack of safety data. ${ }^{83-86}$

- Increased fluids: no evidence for or against, although some evidence from some observational studies that may be harmful. ${ }^{87}$

- Heated or humidified air for the common cold: in some studies this helped, in others it did not; no studies included children. ${ }^{88}$

- Humidified air inhalation for treating croup: three small studies in emergency settings in a total of 135 patients with moderate to severe croup showed there did not appear to be any benefit, but there have been no studies in primary care. ${ }^{89}$

- Non-steroidal anti-inflammatory drugs for the common cold: nine studies with 1064 patients showed improvement in most analgesiarelated symptoms, but no clear evidence of improvement in runny noses or cough. ${ }^{90}$

- Reviews of zinc and the homeopathic remedy, Oscillococcinum, have been withdrawn from the Cochrane database. 
RCTs of interventions incorporating shared decision making during consultations, including the use of an interactive booklet in the consultation, ${ }^{14}$ demonstrated reductions in antibiotic prescribing without adversely effecting recovery or satisfaction with care..$^{14,53,101}$

Public education campaigns. Patients expect antibiotics if they perceive previous benefit from them. ${ }^{96}$ The UK Department of Health sponsored household survey found that one-third of the public still believe that antibiotics work against coughs and colds, and that increased knowledge about antibiotics resulted in patients being more likely to finish the course, keep left-over antibiotics, and self-medicate, but did not reduce the likelihood of being prescribed antibiotics. Young, highly educated women in particular were more likely to store, take, and share antibiotics. ${ }^{102}$ An internet based questionnaire in the Netherlands found similar levels of knowledge and beliefs. ${ }^{103}$ Smokers also are more likely to expect antibiotics and believe that antibiotics are beneficial for acute cough than non-smokers, despite no evidence of benefit. ${ }^{104}$

Strategies aim to reduce patient expectations for antibiotics and encourage self-management. ${ }^{105}$ These have ranged from country-specific public health campaigns aimed at either the whole population or at specific groups. ${ }^{106-109}$ National campaigns in Belgium ${ }^{110}$ and France ${ }^{111,112}$ resulted in meaningful reductions in antibiotic prescribing to ambulatory patients. Public intervention campaigns in the north-east of England were cost-effective in reducing antibiotic prescribing during the years when they were run. ${ }^{113}$ The EU funds an annual Antibiotic Awareness day. ${ }^{107,110,114}$ E-bugs (http://www.e-bug.eu/) teaches school children about the spread of infection, good hygiene practices, and the role of antibiotics.

Delayed prescriptions. A Cochrane review that included nine trials found that delayed prescribing can reduce antibiotic use for acute respiratory infections without harming patients. Delayed prescribing compared to immediate antibiotics was associated with reduced patient satisfaction in three trials, and no difference in two. However, delayed antibiotics may have little advantage over not prescribing them at all where it appears safe to do so. ${ }^{115}$ Nevertheless some clinicians find delayed antibiotics are easier to implement than refusing antibiotics altogether, and a time trend analysis of UK data suggested that delayed prescribing was responsible for a $10-15 \%$ reduction in antibiotic use by children between 1998 and 2003. ${ }^{25}$

Prevention and treatment of seasonal influenza Vaccination. Systematic reviews of the efficacy (ability of the vaccine to prevent confirmed influenza cases), effectiveness (ability of the vaccine to prevent influenza-like illness) and safety of vaccines are limited by lack of current, well-designed RCTs. ${ }^{116-118}$

A systematic review on the use of influenza vaccination for healthy children found evidence of efficacy in children older than 2 years but little evidence for children under 2, no comparisons of safety, and a marked difference between vaccine efficacy and

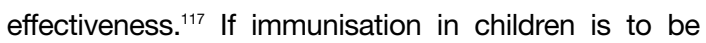
recommended as a public health policy, large-scale studies assessing important outcomes and directly comparing vaccine types are urgently required. A similar review on the use of influenza vaccination for healthy adults found little support for use as a routine public health measure. ${ }^{118}$ Even in older people, the effectiveness of influenza vaccination is modest in long-term care settings and less so in communityresiding residents. ${ }^{116}$

Anti-virals - neuraminidase inhibitors. The recent H1N1 influenza pandemic increased interest in neuraminadase inhibitors in preventing and treating influenza. It is unclear whether data from use in seasonal influenza is applicable to pandemic situations. Two recent systematic reviews, based on evidence from prophylaxis (four trials), treatment (12 trials), and post-exposure prophylaxis (four trials), both concluded that these drugs did not result in meaningful symptomatic improvement in seasonal influenza. ${ }^{119,120}$ Whether oseltamivir reduces influenza-related LRTI complications remains unclear. The 2005 Cochrane systematic review concluded that it did. ${ }^{121}$ However, the most recent Cochrane review withdrew this conclusion on the basis that none of the original studies had been powered to detect differences in severe adverse events, and the authors had been unable to obtain trial data on complications from eight of 10 trials from an originally included meta-analysis. ${ }^{19,121}$

Systematic reviews of the use of neuraminidase inhibitors in children (four trials of treatment and three trials of post-exposure prophylaxis) came to similar conclusions; a small benefit in terms of illness duration and reduced household transmission, but little effect on asthma exacerbations or antibiotic prescribing. ${ }^{123}$

Some strains of influenza virus have developed resistance to existing antivirals amantidine, rimantadine, and the neuraminidase inhibitor, oseltamavir. If we are to preserve the value of antiviral agents, their use must be targeted at those most likely to benefit.

\section{CONCLUSION}

The shared international resource of antimicrobial sensitivity is diminishing and all prescribers have a 'stewardship' responsibility. There are currently few new antibiotics being brought to market, especially for agents effective against gram-negative organisms. ${ }^{124}$ 
Increasing antibiotic resistance is a major public health concern. ${ }^{10,125}$ Even if new antibiotics are brought to market, resistance is likely to emerge with their increasing use. The same is true of antivirals.

Resistant bacterial infections in the community are common and patients with resistant infections are unwell for longer, increase work load in general practice, and increase costs. ${ }^{126-128}$ Recent antibiotic prescribing is the greatest risk factor for carriage of resistance ${ }^{129}$ and for resistant infections. ${ }^{130,131}$ The effect is greatest in the month following treatment, but persists for up to 12 months. ${ }^{131}$ Reducing antibiotic prescribing at practice level impacts favourably on resistance locally. ${ }^{132}$

However, clinicians are rightly concerned about reduced prescribing resulting in potential harm for their patients. Ongoing research into identifying patients likely to benefit from antibiotic treatment and identifying those who can safely be managed without antibiotic treatment is an urgent priority. Nevertheless, as highlighted in this review, there is already considerable evidence that clinicians can draw on to enhance the quality of their antibiotic prescribing decisions. Advances in biomedicine will help patients most if applied in the context of enhanced consultation skills that effectively involve patients in reaching and owning evidence-based prescribing decisions. This will further help manage the burden of uncertainty that is inherent to managing RTIs in primary care.

\section{Acknowledgments}

Naomi Stanton and Nick Francis are supported by the Wales School of Primary Care Research.

\section{Competing interests}

The authors have stated that there are none.

\section{Discuss this article}

Contribute and read comments about this article on the Discussion Forum: http://www.rcgp.org.uk/bjgp-discuss

\section{REFERENCES}

1. Bullowa JG. Pneumonia due to Pneumococcus Type Xiv (Cooper) and its treatment with specific antiserum. J Clin Invest 1935; 14(4):373-383.

2. Cosby JL, Francis N, Butler CC. The role of evidence in the decline of antibiotic use for common respiratory infections in primary care. Lancet Infect Dis 2007; 7(11): 749-756.

3. Ashworth $\mathrm{M}$, Charlton J, Ballard $\mathrm{K}$, et al. Variations in antibiotic prescribing and consultation rates for acute respiratory infection in UK general practices 1995-2000. Br J Gen Pract 2005; 55(517): 603-608.

4. Meropol SB, Chen Z, Metlay JP. Reduced antibiotic prescribing for acute respiratory infections in adults and children. Br J Gen Pract 2009; 59(567) e321-e328.

5. Petersen I, Hayward AC. Antibacterial prescribing in primary care. $J$ Antimicrob Chemother 2007; 60 Suppl 1: i43-47.

6. Little P, Gould C, Williamson I, et al. Reattendance and complications in a randomised trial of prescribing strategies for sore throat: the medicalising effect of prescribing antibiotics. BMJ 1997; 315(7104): 350-352.

7. Simpson SA, Wood F, Butler CC. General practitioners' perceptions of antimicrobial resistance: a qualitative study. J Antimicrob Chemother 2007; 59(2): 292-296.

8. Butler CC, Hood K, Verheij T, et al. Variation in antibiotic prescribing and its impact on recovery in patients with acute cough in primary care: prospective study in 13 countries. BMJ 2009; 338: b2242.

9. Van Duijn HJ, Kuyvenhoven MM, Butler CC, et al. Variation in outpatient antibiotic use in three European countries: exploration of possible determinants. Eur J Gen Pract 2005; 11(3-4): 139-140.

10. Goossens H, Ferech M, Vander Stichele R, Elseviers M. Outpatient antibiotic use in Europe and association with resistance: a cross-national database study. Lancet 2005; 365(9459): 579-587.

11. Wang KY, Seed P, Schofield P, et al. Which practices are high antibiotic prescribers? A cross-sectional analysis. Br J Gen Pract 2009; 59(567): 315-320.

12. NICE Short Clinical Guidelines Technical Team. Respiratory tract infections - antibiotic prescribing. Prescribing of antibiotics for self-limiting respiratory tract infections in adults and children in primary care. CG69/ London: National Institute for Health and Clinical Excellence, 2008.

13. Butler CC, Hood K, Kinnersley P, et al. Predicting the clinical course of suspected acute viral upper respiratory tract infection in children. Fam Pract 2005; 22(1): 92-95.

14. Francis NA, Butler CC, Hood K, et al. Effect of using an interactive booklet about childhood respiratory tract infections in primary care consultations on reconsulting and antibiotic prescribing: a cluster randomised controlled trial. BMJ 2009; 339: b2885.

15. Macfarlane J, Prewett J, Rose D, et al. Prospective case-control study of role of infection in patients who reconsult after initial antibiotic treatment for lower respiratory tract infection in primary care. BMJ 1997; 315(7117): 1206-1210.

16. Cals JW, Hood K, Aaftink N, et al. Predictors of patient-initiated reconsultation for lower respiratory tract infections in general practice. $\mathrm{Br}$ J Gen Pract 2009; 59(567): 761-764

17. Macfarlane JT, Holmes WF, Macfarlane RM. Reducing reconsultations for acute lower respiratory tract illness with an information leaflet: a randomized controlled study of patients in primary care. Br J Gen Pract 1997; 47(424): 719-722.

18. Bennike T, Brochner-Mortensen K, Kjaer E, et al. Penicillin therapy in acute tonsillitis, phlegmonous tonsillitis and ulcerative tonsillitis. Acta Med Scand 1951; 139(4): 253-274.

19. Zwart S, Sachs AP, Ruijs GJ, et al. Penicillin for acute sore throat: randomised double blind trial of seven days versus three days treatment or placebo in adults. BMJ 2000; 320(7228): 150-154.

20. Dagnelie CF, van der Graaf Y, De Melker RA. Do patients with sore throat benefit from penicillin? A randomized double-blind placebo-controlled clinical trial with penicillin V in general practice. Br J Gen Pract 1996; 46(411): 589-593.

21. Howe RW, Millar MR, Coast J, et al. A randomized controlled trial of antibiotics on symptom resolution in patients presenting to their general practitioner with a sore throat. Br J Gen Pract 1997; 47(418): 280-284.

22. Dunn N, Lane D, Everitt H, Little P. Use of antibiotics for sore throat and incidence of quinsy. Br J Gen Pract 2007; 57(534): 45-49.

23. Petersen I, Johnson AM, Islam A, et al. Protective effect of antibiotics against serious complications of common respiratory tract infections: retrospective cohort study with the UK General Practice Research Database. BMJ 2007; 335(7627): 982.

24. Thompson PL, Gilbert RE, Long PF, et al. Effect of antibiotics for otitis media on mastoiditis in children: a retrospective cohort study using the United Kingdom general practice research database. Pediatrics 2009; 123(2): $424-430$

25. Sharland $\mathrm{M}$, Kendall $\mathrm{H}$, Yeates $\mathrm{D}$, et al. Antibiotic prescribing in general practice and hospital admissions for peritonsillar abscess, mastoiditis, and rheumatic fever in children: time trend analysis. $B M J 2005 ; 331$ (7512): 328-329.

26. Trotter CL, Stuart JM, George R, Miller E. Increasing hospital admissions for pneumonia, England. Emerg Infect Dis 2008; 14(5): 727-733.

27. Roxburgh CS, Youngson GG, Townend JA, Turner SW. Trends in pneumonia and empyema in Scottish children in the past 25 years. Arch Dis Child 2008; 93(4): 316-318.

28. Price DB, Honeybourne D, Little P, et al. Community-acquired pneumonia mortality: a potential link to antibiotic prescribing trends in general practice. Respir Med 2004; 98(1): 17-24.

29. Van Duijn HJ, Kuyvenhoven MM, Tiebosch HM, et al. Diagnostic labelling as determinant of antibiotic prescribing for acute respiratory tract episodes in general practice. BMC Fam Pract 2007; 8: 55.

30. Winchester CC, Macfarlane TV, Thomas M, Price D. Antibiotic prescribing and outcomes of lower respiratory tract infection in UK primary care. Chest 2009; 135(5): 1163-1172.

31. Craig JC, Williams GJ, Jones M, et al. The accuracy of clinical symptoms and signs for the diagnosis of serious bacterial infection in young febrile children: prospective cohort study of 15781 febrile illnesses. BMJ 2010; 340: $\mathrm{c} 1594$.

32. Del Mar CB, Glasziou PP, Spinks AB. Antibiotics for sore throat. Cochrane 
Database Syst Rev 2006; (4): CD000023.

33. Komaroff AL, Pass TM, Aronson MD, et al. The prediction of streptococcal pharyngitis in adults. J Gen Intern Med 1986; 1(1): 1-7.

34. Walsh BT, Bookheim WW, Johnson RC, Tompkins RK. Recognition of streptococcal pharyngitis in adults. Arch Intern Med 1975; 135(11): 1493-1497.

35. Centor RM, Witherspoon JM, Dalton HP, et al. The diagnosis of strep throat in adults in the emergency room. Med Decis Making 1981; 1(3): 239-246.

36. Foong HB, Yassim M, Chia YC, Kang BH. Streptococcal pharyngitis in a primary care clinic. Singapore Med J 1992; 33(6): 597-599.

37. Seppala $\mathrm{H}$, Lahtonen R, Ziegler $\mathrm{T}$, et al. Clinical scoring system in the evaluation of adult pharyngitis. Arch Otolaryngol Head Neck Surg 1993; 119(3): 288-291

38. Shank JC, Powell TA. A five-year experience with throat cultures. J Fam Pract 1984; 18(6): 857-863.

39. Humair JP, Revaz SA, Bovier P, Stalder H. Management of acute pharyngitis in adults: reliability of rapid streptococcal tests and clinical findings. Arch Intern Med 2006; 166(6): 640-644.

40. Kaplan EL, Top FH Jr, Dudding BA, Wannamaker LW. Diagnosis of streptococcal pharyngitis: differentiation of active infection from the carrier state in the symptomatic child. J Infect Dis 1971; 123(5): 490-501.

41. Steinhoff MC, Abd el Khalek MK, Khallaf N, et al. Effectiveness of clinical guidelines for the presumptive treatment of streptococcal pharyngitis in Egyptian children. Lancet 1997; 350(9082): 918-921.

42. McIsaac WJ, Butler CC. Does clinical error contribute to unnecessary antibiotic use? Med Decis Making 2000; 20(1):33-38.

43. McIsaac WJ, Goel V, To T, Low DE. The validity of a sore throat score in family practice. CMAJ 2000; 163(7): 811-815.

44. Ebell MH, Smith MA, Barry HC, et al. The rational clinical examination Does this patient have strep throat? JAMA 2000; 284(22): 2912-2918.

45. Holm A, Nexoe J, Bistrup LA, et al. Aetiology and prediction of pneumonia in lower respiratory tract infection in primary care. $\mathrm{Br} J \mathrm{Gen}$ Pract 2007; 57(540): 547-554.

46. Hopstaken RM, Butler CC, Muris JW, et al. Do clinical findings in lower respiratory tract infection help general practitioners prescribe antibiotics appropriately? An observational cohort study in general practice. Fam Pract 2006; 23(2): 180-187.

47. Holmes WF, Macfarlane JT, Macfarlane RM, Hubbard R. Symptoms, signs, and prescribing for acute lower respiratory tract illness. Br J Gen Pract 2001; 51(464): 177-181.

48. Metlay JP, Kapoor WN, Fine MJ. Does this patient have communityacquired pneumonia? Diagnosing pneumonia by history and physical examination. JAMA 1997; 278(17): 1440-1445.

49. Dinant GJ, Buntinx FF, Butler CC. The necessary shift from diagnostic to prognostic research. BMC Fam Pract 2007; 8: 53.

50. Van der Meer V, Neven AK, van den Broek PJ, Assendelft WJ. Diagnostic value of $C$ reactive protein in infections of the lower respiratory tract: systematic review. BMJ 2005; 331(7507): 26

51. Holm A, Pedersen SS, Nexoe J, et al. Procalcitonin versus C-reactive protein for predicting pneumonia in adults with lower respiratory tract infection in primary care. Br J Gen Pract 2007; 57(540): 555-560.

52. Schuetz P, Christ-Crain M, Thomann R, et al. Effect of procalcitoninbased guidelines vs standard guidelines on antibiotic use in lower respiratory tract infections: the ProHOSP randomized controlled trial. JAMA 2009; 302(10): 1059-1066.

53. Cals JW, Butler CC, Hopstaken RM, et al. Effect of point of care testing for $\mathrm{C}$ reactive protein and training in communication skills on antibiotic use in lower respiratory tract infections: cluster randomised trial. BMJ 2009; 338: b1374.

54. Butler CC, Simpson S, Wood F. General practitioners' perceptions of introducing near-patient testing for common infections into routine primary care: a qualitative study. Scand J Prim Health Care 2008; 26(1): $17-21$.

55. McIsaac WJ, Kellner JD, Aufricht P, et al. Empirical validation of guidelines for the management of pharyngitis in children and adults. JAMA 2004; 291(13): 1587-1595.

56. Lindbaek M, Hoiby EA, Lermark G, et al. Which is the best method to trace group A streptococci in sore throat patients: culture or GAS antigen test? Scand J Prim Health Care 2004; 22(4): 233-238.

57. Hjortdahl P, Melbye H. Does near-to-patient testing contribute to the diagnosis of streptococcal pharyngitis in adults? Scand J Prim Health Care 1994; 12(2): 70-76.

58. Hussain M, Melegaro A, Pebody RG, et al. A longitudinal household study of Streptococcus pneumoniae nasopharyngeal carriage in a UK setting. Epidemiol Infect 2005; 133(5): 891-898.

59. Doan Q, Enarson P, Kissoon N, et al. Rapid viral diagnosis for acute febrile respiratory illness in children in the Emergency Department. Cochrane Database Syst Rev 2009; (4): CD006452.

60. Centers for Disease Control and Prevention. Rapid Diagnostic Testing for Influenza. http://www.cdc.gov/flu/professionals/diagnosis/rapidlab.htm (accessed 9 Nov 2010).

61. Centers for Disease Control and Prevention. Laboratory Testing. http://www.cdc.gov/rsv/clinical/labtesting.html (accessed 9 Nov 2010).

62. WHO. WHO recommendations on the use of rapid testing for influenza diagnosis. Geneva, Switzerland: WHO, 2005.

63. Vinogradova Y, Hippisley-Cox J, Coupland C. Identification of new risk factors for pneumonia: population-based case-control study. Br J Gen Pract 2009; 59(567): e329-e338.

64. Venmans LM, Bont J, Gorter KJ. Prediction of complicated lower respiratory tract infections in older patients with diabetes. Br J Gen Pract 2008; 58(553):564-568.

65. Van de Nadort C, Smeets HM, Bont J, et al. Prognosis of primary care patients aged 80 years and older with lower respiratory tract infection. $\mathrm{Br}$ J Gen Pract 2009; 59(561): e110-el15.

66. Jordan RE, Hawker JI, Ayres JG, et al. Effect of social factors on winter hospital admission for respiratory disease: a case-control study of older people in the UK. Br J Gen Pract 2008; 58(551): 400-402.

67. Carratala J, Fernandez-Sabe N, Ortega L, et al. Outpatient care compared with hospitalization for community-acquired pneumonia: a randomized trial in low-risk patients. Ann Intern Med 2005; 142(3): 165-172.

68. Coley CM, Li YH, Medsger AR, et al. Preferences for home vs hospital care among low-risk patients with community-acquired pneumonia. Arch Intern Med 1996; 156(14): 1565-1571.

69. Bauer TT, Ewig S, Marre R, et al. CRB-65 predicts death from community-acquired pneumonia. J Intern Med 2006; 260(1): 93-101.

70. Ewig S, Torres A, Woodhead M. Assessment of pneumonia severity: a European perspective. Eur Respir J 2006; 27(1): 6-8.

71. Chalmers JD, Singanayagam A, Hill AT. Systolic blood pressure is superior to other haemodynamic predictors of outcome in community acquired pneumonia. Thorax 2008; 63(8): 698-702.

72. Capelastegui A, Espana PP, Quintana JM, et al. Validation of a predictive rule for the management of community-acquired pneumonia. Eur Respir J 2006; 27(1): 151-157.

73. Lim WS, Macfarlane JT. Defining prognostic factors in the elderly with community acquired pneumonia: a case controlled study of patients aged $>$ or $=75$ yrs. Eur Respir J 2001; 17(2): 200-205.

74. Smucny J, Becker L, Glazier R. Beta2-agonists for acute bronchitis Cochrane Database Syst Rev 2006; (4): CD001726.

75. Smith SM, Schroeder K, Fahey T. Over-the-counter medications for acute cough in children and adults in ambulatory settings. Cochrane Database Syst Rev 2008; (1): CD001831.

76. MRHA. Children's over-the-counter cough and cold medicines: New advice.

http://www.mhra.gov.uk/Safetyinformation/Safetywarningsalertsandrecal ls/Safetywarningsandmessagesformedicines/CON038908 (accessed 9 Nov 2010).

77. Hayward G, Thompson M, Heneghan C, et al. Corticosteroids for pain relief in sore throat: systematic review and meta-analysis. BMJ 2009; 339: b2976.

78. Hemila $\mathrm{H}$, Louhiala P. Vitamin C for preventing and treating pneumonia. Cochrane Database Syst Rev 2007; (1): CD005532.

79. Douglas RM, Hemila H, Chalker E, Treacy B. Vitamin C for preventing and treating the common cold. Cochrane Database Syst Rev 2007; (3): CD000980.

80. Chen $\mathrm{H}$, Zhuo Q, Yuan W, et al. Vitamin A for preventing acute lower respiratory tract infections in children up to seven years of age. Cochrane Database Syst Rev 2008; (1): CD006090.

81. Linde K, Barrett B, Wolkart K, et al. Echinacea for preventing and treating the common cold. Cochrane Database Syst Rev 2006; (1): CD000530.

82. Lissiman E, Bhasale AL, Cohen M. Garlic for the common cold. Cochrane Database Syst Rev 2009; (3): CD006206.

83 Wei J, Ni J, Wu T, et al. Chinese medicinal herbs for acute bronchitis. Cochrane Database Syst Rev 2008; (1): CD004560.

84. Chen XY, Wu TX, Liu GJ, et al. Chinese medicinal herbs for influenza. Cochrane Database Syst Rev 2007; (4): CD004559.

85. Shi Y, Gu R, Liu C, et al. Chinese medicinal herbs for sore throat. Cochrane Database Syst Rev 2007; (3): CD004877. 
86. Wu T, Zhang J, Qiu Y, et al. Chinese medicinal herbs for the common cold. Cochrane Database Syst Rev 2007; (1): CD004782.

87. Guppy MP, Mickan SM, Del Mar CB. Advising patients to increase fluid intake for treating acute respiratory infections. Cochrane Database Syst Rev 2005; (4): CD004419.

88. Singh M. Heated, humidified air for the common cold. Cochrane Database Syst Rev 2006; (3): CD001728.

89. Moore M, Little P. Humidified air inhalation for treating croup. Cochrane Database Syst Rev 2006; (3): CD002870.

90. Kim SY, Chang YJ, Cho HM, et al. Non-steroidal anti-inflammatory drugs for the common cold. Cochrane Database Syst Rev 2009; (3): CD006362

91. Macfarlane J, Holmes W, Macfarlane R, Britten N. Influence of patients expectations on antibiotic management of acute lower respiratory tract illness in general practice: questionnaire study. BMJ 1997; 315(7117): $1211-1214$

92. Vinson DC, Lutz LJ. The effect of parental expectations on treatment of children with a cough: a report from ASPN. J Fam Pract 1993; 37(1): 23-27.

93. Van Duijn HJ, Kuyvenhoven MM, Schellevis FG, Verheij TJ. Illness behaviour and antibiotic prescription in patients with respiratory tract symptoms. Br J Gen Pract 2007; 57(540): 561-568.

94. Linder JA, Singer DE. Desire for antibiotics and antibiotic prescribing for adults with upper respiratory tract infections. J Gen Intern Med 2003; 18(10): 795-801.

95. Van Driel ML, De Sutter A, Deveugele M, et al. Are sore throat patients who hope for antibiotics actually asking for pain relief? Ann Fam Med 2006; 4(6): 494-499.

96. Dosh SA, Hickner JM, Mainous AG III, Ebell MH. Predictors of antibiotic prescribing for nonspecific upper respiratory infections, acute bronchitis, and acute sinusitis. An UPRNet study. Upper Peninsula Research Network. J Fam Pract 2000; 49(5): 407-414.

97. Cockburn J, Pit S. Prescribing behaviour in clinical practice: patients expectations and doctors' perceptions of patients' expectations - a questionnaire study. $B M J$ 1997; 315(7107): 520-523.

98. Little P, Dorward M, Warner G, et al. Importance of patient pressure and perceived pressure and perceived medical need for investigations, referral, and prescribing in primary care: nested observational study. BMJ 2004; 328(7437): 444.

99. Coenen S, Michiels B, Renard D, et al. Antibiotic prescribing for acute cough: the effect of perceived patient demand. Br J Gen Pract 2006; 56(524): 183-190

100. Butler CC, Rollnick S, Kinnersley P, et al. Communicating about expected course and re-consultation for respiratory tract infections in children: an exploratory study. Br J Gen Pract 2004; 54(504): 536-538.

101. Butler CC, Kinnersley P, Prout H, et al. Antibiotics and shared decisionmaking in primary care. J Antimicrob Chemother 2001; 48(3): 435-440.

102. McNulty CA, Boyle P, Nichols T, et al. The public's attitudes to and compliance with antibiotics. J Antimicrob Chemother 2007; 60 Suppl 1: i63-68.

103. Cals JW, Boumans D, Lardinois RJ, et al. Public beliefs on antibiotics and respiratory tract infections: an internet-based questionnaire study. $\mathrm{Br} \mathrm{J}$ Gen Pract 2007; 57(545): 942-947.

104. Stanton N, Hood K, Kelly MJ, et al. Are smokers with acute cough in primary care prescribed antibiotics more often, and to what benefit? An observational study in 13 European countries. Eur Respir J 2010; 35(4): 761-767.

105. Davey P, Pagliari C, Hayes A. The patient's role in the spread and control of bacterial resistance to antibiotics. Clin Microbiol Infect 2002; 8 Suppl 2: 43-68.

106. Huttner B GH, Goossens H, Verheij T, et al. Characteristics and outcomes of public campaigns aimed at improving the use of antibiotics in outpatients in high-income countries. Lancet Infect Dis 2010; 10(1): $17-31$.

107. Coenen S, Costers M, De Corte S, et al. The first European Antibiotic Awareness Day after a decade of improving outpatient antibiotic use in Belgium. Acta Clin Belg 2008; 63(5): 296-300.

108. Coenen S, Costers M, Goossens H. Comment on: can mass media campaigns change antimicrobial prescribing? A regional evaluation study I Antimicrob Chemother 2007; 60(1): 179-180.

109. Earnshaw S, Monnet DL, Duncan B, et al. European Antibiotic Awareness Day, 2008 - the first Europe-wide public information campaign on prudent antibiotic use: methods and survey of activities in participating countries. Euro Surveill 2009; 14(30): 19280.

110. Goossens H, Guillemot D, Ferech M, et al. National campaigns to improve antibiotic use. Eur J Clin Pharmacol 2006; 62(5): 373-379.

111. Huttner B, Harbarth S. 'Antibiotics are not automatic anymore' — the French national campaign to cut antibiotic overuse. PLoS Med 2009; 6(6): e1000080.

112. Sabuncu E, David J, Bernede-Bauduin C, et al. Significant reduction of antibiotic use in the community after a nationwide campaign in France, 2002-2007. PLoS Med 2009; 6(6): e1000084.

113. Lambert MF, Masters GA, Brent SL. Can mass media campaigns change antimicrobial prescribing? A regional evaluation study. J Antimicrob Chemother 2007; 59(3): 537-543.

114. Finch R, Sharland M. 18 November and beyond: observations on the EU Antibiotic Awareness Day. J Antimicrob Chemother 2009; 63(4): 633-635.

115 Spurling GK, Del Mar CB, Dooley L, Foxlee R. Delayed antibiotics for respiratory infections. Cochrane Database Syst Rev 2007; (3): CD004417

116. Rivetti D, Jefferson T, Thomas R, et al. Vaccines for preventing influenza in the elderly. Cochrane Database Syst Rev 2006; (3): CD004876.

117. Jefferson T, Rivetti A, Harnden A, et al. Vaccines for preventing influenza in healthy children. Cochrane Database Syst Rev 2008; (2): CD004879.

118. Jefferson TO, Rivetti D, Di Pietrantonj C, et al. Vaccines for preventing influenza in healthy adults. Cochrane Database Syst Rev 2007; (2): CD001269.

119. Jefferson T, Jones M, Doshi P, Del Mar C. Neuraminidase inhibitors for preventing and treating influenza in healthy adults: systematic review and meta-analysis. BMJ 2009; 339: b5106.

120. Burch J, Paulden M, Conti S, et al. Antiviral drugs for the treatment of influenza: a systematic review and economic evaluation. Health Technol Assess 2009; 13(58): 1-265, iii-iv.

121. Jefferson TO, Demicheli V, Di Pietrantonj C, et al. Neuraminidase inhibitors for preventing and treating influenza in healthy adults. Cochrane Database Syst Rev 2006; (3): CD001265.

122. Kaiser L, Wat C, Mills T, et al. Impact of oseltamivir treatment on influenza-related lower respiratory tract complications and hospitalizations. Arch Intern Med 2003; 163(14): 1667-1672.

123. Shun-Shin M, Thompson M, Heneghan C, et al. Neuraminidase inhibitors for treatment and prophylaxis of influenza in children: systematic review and meta-analysis of randomised controlled trials. BMJ 2009; 339: b3172.

124. Boucher HW, Talbot GH, Bradley JS, et al. Bad bugs, no drugs: no ESKAPE! An update from the Infectious Diseases Society of America. Clin Infect Dis 2009; 48(1): 1-12.

125. Cars O, Hogberg LD, Murray M, et al. Meeting the challenge of antibiotic resistance. $B M J$ 2008; 337: al438.

126. Butler CC, Hillier S, Roberts Z, et al. Antibiotic-resistant infections in primary care are symptomatic for longer and increase workload: outcomes for patients with E. coli UTIs. Br J Gen Pract 2006; 56(530): 686-692.

127. McNulty CA, Richards J, Livermore DM, et al. Clinical relevance of laboratory-reported antibiotic resistance in acute uncomplicated urinary tract infection in primary care. J Antimicrob Chemother 2006; 58(5): 1000-1008.

128. Alam MF, Cohen D, Butler C, et al. The additional costs of antibiotics and re-consultations for antibiotic-resistant Escherichia coli urinary tract infections managed in general practice. Int J Antimicrob Agents 2009; 33(3): 255-257.

129. Hay AD, Thomas M, Montgomery A, et al. The relationship between primary care antibiotic prescribing and bacterial resistance in adults in the community: a controlled observational study using individual patient data. J Antimicrob Chemother 2005; 56(1): 146-153.

130. Hillier S, Roberts Z, Dunstan F, et al. Prior antibiotics and risk of antibiotic-resistant community-acquired urinary tract infection: a casecontrol study. J Antimicrob Chemother 2007; 60(1): 92-99.

131. Costelloe C, Metcalfe C, Lovering A, et al. Effect of antibiotic prescribing in primary care on antimicrobial resistance in individual patients: systematic review and meta-analysis. BMJ 2010; 340: c2096.

132. Butler CC, Dunstan F, Heginbothom M, et al. Containing antibiotic resistance: decreased antibiotic-resistant coliform urinary tract infections with reduction in antibiotic prescribing by general practices. $\mathrm{Br} J \mathrm{Gen}$ Pract 2007; 57(543): 785-792. 